

COMMUNICATION How English became the lingua franca of science p.154
SUSTAINABILITY Primer from superstar academic is required reading $\mathbf{p} .156$
REPRODUCIBILITY CURb

poor conduct as well as misconduct $\mathbf{p} .158$
OBITUARY Yves Chauvin, Nobel-winning chemist, remembered $\mathbf{p . 1 5 9}$

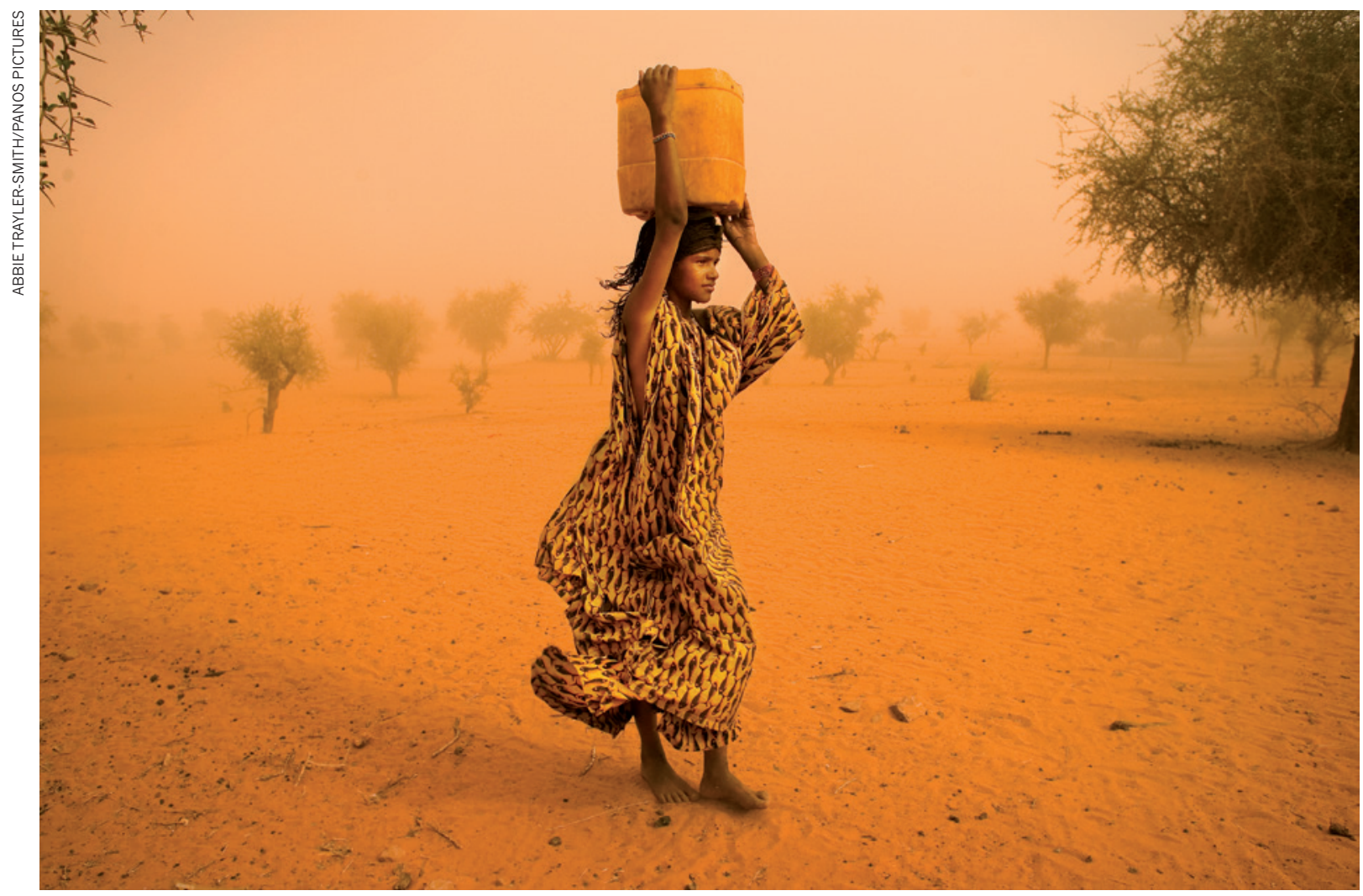

A Tuareg woman carries water through a sandstorm in drought-ridden Mali.

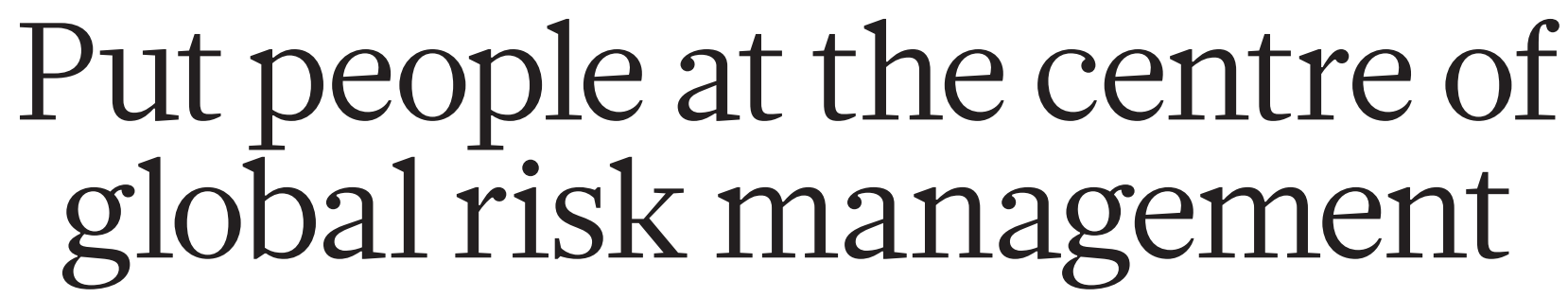

An individual focus is needed to assess interconnected threats and build resilience worldwide, urge Jan Willem Erisman and colleagues.

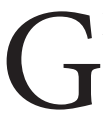
lobalization is changing the nature of risk. Natural and social systems - from climate to energy, food, water and economies - are tightly coupled. Abrupt changes in one have a domino effect on others. Floods in Thailand in 2010, for example, led to a global shortage of computer hard disks as a result of factories closing, as well as more than US\$330 million in damage and around 250 deaths.
}

The exposure of people and assets to risks is increasing worldwide. From 1980 to 2012, annual economic losses from environmental disasters rose more than sevenfold, from about $\$ 20$ billion to $\$ 150$ billion a year ${ }^{1}$.

Yet most risk assessments ignore networked threats ${ }^{2,3}$. The annual Global Risks report of the World Economic Forum considers risks qualitatively, based on the views of experts ${ }^{4}$. But global outlooks remain sectorial and too coarse to guide individuals, organizations, municipalities or nations.

Risk reports also neglect the collective impacts of personal choices ${ }^{3}$. For example, eating more beef causes deforestation and biodiversity loss in the Amazon. Local dams for hydropower or water storage alter sediment flows to fertile coastal regions. The movement of people from the $>$ 



Global risks and losses from extreme weather, as in Thailand's 2010 floods, and agricultural failures, such as locusts destroying crops in Madagascar, are rising.

countryside to cities affects water, food, climatic and energy systems planet-wide.

Understanding networked risks is essential for achieving the United Nations Sustainable Development Goals, which are being defined this year ${ }^{5}$. The 17 proposed goals are interdependent. For example, the stimulation of renewable energies and biofuels to address climate change also affects food production and water resources.

\section{BROAD FOCUS}

We propose a systems-based approach for quantifying risk that integrates individual responses and considers the transfer of information and feedback mechanisms across networks (see 'Safety secured'). Such an approach identifies pinch points - geographic, economic and social - so that key systems and individual behaviours can be made more sustainable and resilient.
Current global-change risk assessments take a top-down approach and target single stressors, such as the climate. They focus on the most vulnerable and at-risk communities, infrastructure, sectors, ecosystems and areas. Links between extreme weather and climate change have begun to be addressed, but wider impacts on land degradation, food and energy production, water supply and environmental hazards have not.

Disaster-reduction frameworks, such as the UN Post-2015 Development Agenda, which will be agreed this month in Japan, aim to improve reactions to adverse events once they have happened. But the UN agenda does not promote resilience in general or help stakeholders such as farmers or municipal leaders to manage multiple risks.

Programmes for delivering knowledge about risk to sectors of society are too narrow.

\section{SAFETY SECURED}

Promoting overall resilience (left) rather than managing many individual risks (right) is the best way to minimize impacts from adverse events.

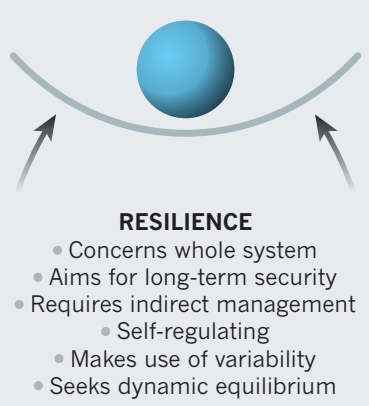

Seeks dynamic equilibrium



RISK MANAGEMENT

Focuses on single risks

- Aims for short-term security

- Requires direct intervention

Needs continuous monitoring

- Eliminates variability

- Seeks static equilibrium
Climate services inform the agriculture and insurance sectors about climate change. But their academic focus does not serve corporate clients, who want climate data packaged into products that they can use to manage, for example, exposure to market disruptions or rising energy prices.

The Climate Corporation in San Francisco, California, sells weather and agronomic data-monitoring and modelling tools to farmers. But its products do not, for instance, consider other impacts such as the risks of air and water pollution associated with the use of nitrogen fertilizers ${ }^{6}$.

Approaches to communicating a broader set of global risks appeal to researchers and policy-makers. For example, the 'planetary boundaries' concept ${ }^{7}$ identifies tipping points in nine key Earth systems (including climate change, biodiversity and the nitrogen cycle) above which Earth's habitability would be threatened. But global limits are difficult to translate into targets or strategies that are meaningful for a particular company, city or region.

How then should scientists, insurance companies, policy-makers and other stakeholders combine risk assessments across scales, stressors and sectors?

\section{USER FIRST}

We argue that Earth-system risk management should follow the example of health-care sys tems, in which emphasis is switching from medicalization to supporting people's ability to adapt and self-manage ${ }^{8}$. Collectively, individual choices feed back into the community and help it to lower its health risks. 




Risk management must therefore start with the users - be they people, organizations, municipalities or nations. Risks should be identified and prioritized in expanding circles around the user (see 'Networked threats'), from local and shortterm risks to more distant and long-term related global threats.

Take food. Supplies are threatened by elevated production costs, ecosystem, water and soil-quality impairment, food wastage and nutrient losses, poor food distribution and alienation of consumers from producers. Yet farmers consider only immediate factors - maximizing yields, avoiding disease and short-term price fluctuations when deciding how and when to plant crops.

In our approach, farmers would also consider climate change, energy prices, floods and droughts and ecosystem services. The wider ecological and social repercussions of personal decisions such as whether to use more fertilizer or pesticides, expand soil tillage or irrigation would become more apparent. Worldwide, $10 \%$ of farmers manage $70 \%$ of the agricultural land, so the side effects of such localized choices can be widespread.

\section{RADICAL REFRAMING}

In practical terms, a networked risk-assessment model should combine standard techniques for individual risk assessments (such as those set out for enterprises by the International Organization for Standardization) with a mechanism to capture the complexities of human behaviour. One such method is agent-based modelling ${ }^{9}$, which uses simulations of a collection of computational

\section{NETWORKED THREATS}

As well as immediate risks such as droughts and floods, individuals should factor in remote threats such as climate change into their decisions. If risks from the local to the global and connections between them are assessed, people can choose effective actions that build resilience.

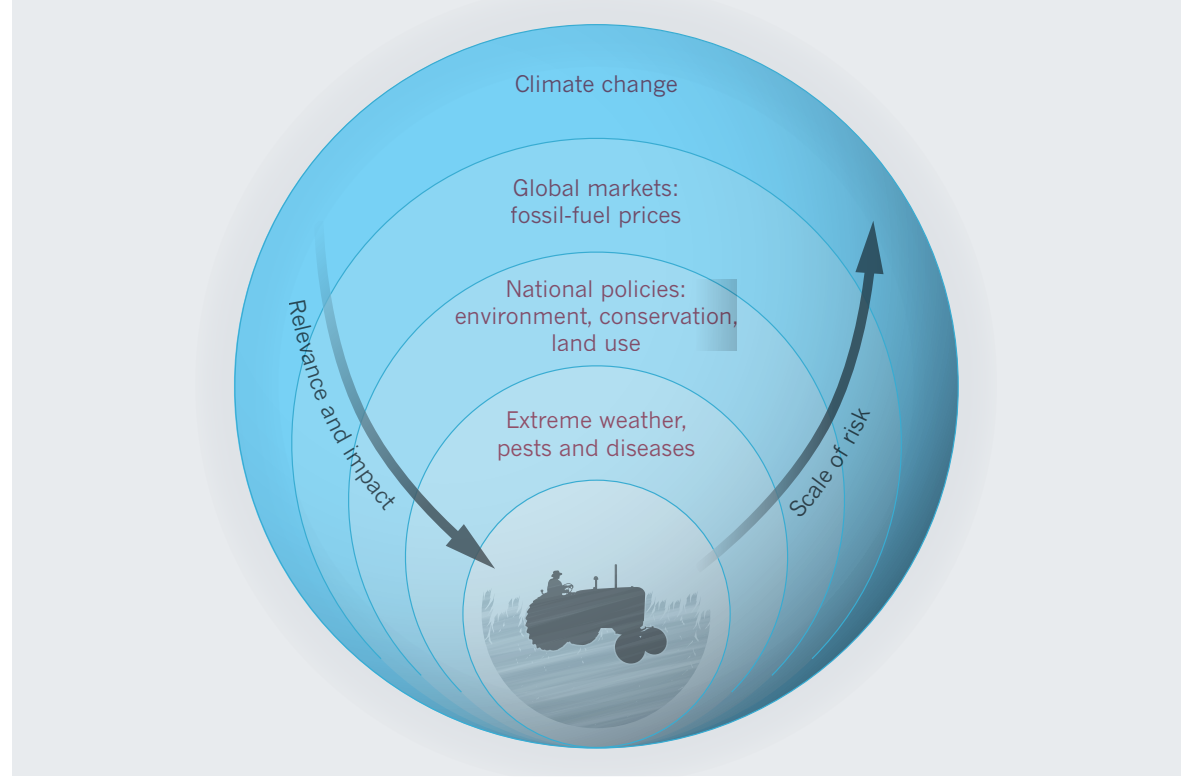

entities that interact according to a set of mathematical rules. This approach has been used to model stock-market trends, traffic flows and the spread of epidemics.

Two major shifts in thinking are needed to deliver the global risk-network model. First, the risk narrative needs to be reframed to put the individual at the centre. Second, risk modelling should adapt to take a broad focus - encompassing environmental and socio-economic risks across the whole Earth system.

The UN's sustainability and disasterreduction programmes should adopt this user-centric focus and redirect their existing efforts. The UN-led Global Framework for Climate Services should be similarly extended to include inventories of issues that matter to the individual (collated through platforms such as the UN website vote.myworld2015.org).

Relevant risks at particular scales will need to be defined and methods for analysing them jointly developed. Future Earth, a global research hub launching this year to provide the knowledge and support to accelerate transformations to a sustainable world, should coordinate the research.

Partnerships must be built across disciplines to supply and share data and analysis tools. Practitioners from the private and public sectors will need to work with economists, engineers, social scientists, information specialists and climate and Earth-system experts.

Investment by public-private partnerships will be essential to amass the necessary resources, maximize uptake of this multiscale approach, stimulate innovation from industry and guarantee that the user's needs are at the core. As the cost of disasters increases each year, the impetus for both governments and industry to invest in risk management and resilience is clear.

Jan Willem Erisman is director of the Louis Bolk Institute in Driebergen, the Netherlands. Guy Brasseur is a senior scientist at the Max Planck Institute for Meteorology in Hamburg, Germany. Philippe Ciais is a senior researcher at the Laboratory for Climate Sciences and the Environment, University of Versailles, France. Nick van Eekeren is senior researcher at the Louis Bolk Institute in Driebergen, the Netherlands. Thomas L. Theis is director of the Institute for Environmental Science and Policy, University of Illinois at Chicago, USA. e-mail:j.erisman@louisbolk.nl

1. Guha-Sapir, D., Hoyois, P. \& Below, R. Annual Disaster Statistical Review 2013: The Numbers and Trends (Centre for Research on the Epidemiology of Disasters, 2014).

2. Helbing, D. Nature 497, 51-59 (2013)

3. Adger, W. N., Eakin, H. \& Winkels, A. Front. Ecol. Environ. 7, 150-157 (2009).

4. World Economic Forum. Global Risks 2015 (WEF, 2015).

5. Open Working Group of the General Assembly on Sustainable Development Goals. Open Working Group Proposal for Sustainable Development Goals (United Nations, 2014)

6. Erisman, J. W., Sutton, M. A., Galloway, J., Klimont, Z. \& Winiwarter, W. Nature Geosci. 1, 636-639 (2008)

7. Rockström, J. et al. Nature 461, 472-475 (2009)

8. Huber, M., Knottnerus, J. A., Green L. et al. Br. Med. J. 343, 235-237 (2011).

9. Gilbert, N. Agent-based Models (Sage, 2007). 